\title{
The Iron Age stone tool assemblage of Gird-i Bazar, in the Kurdish Autonomous Region of Iraq
}

\author{
Andrea Squitieri
}

Keywords: Iron Age, stone tools, Iraqi Kurdistan, Neo-Assyrian Empire

\section{Introduction}

\subsection{The geographic and geological setting}

Gird-i Bazar (38N E 512696; N 3999290; 540 m altitude) is a small and shallow mound of about 0.5 ha located in the Bora Plain, a sub-unit of the much larger Peshdar Plain, in the Sulaymaniyah Province of the Kurdish Autonomous Region of Iraq (Fig. 1). The Peshdar Plain is located about $70 \mathrm{~km}$ northwest of Sulaymaniyah. It is bordered to the east by the Zagros Mountains and the Iranian border; to the west it is separated from the Ranyah Plain by a mountain range which itself is interrupted by a passage called Darband-i Ranyah. Here, the Lesser Zab, the river that borders the Peshdar Plain to the south, breaks through to flow into the artificial Dokan Lake. The main centre of the Peshdar Plain is the town of Qalat Dizeh (or Qaladze) (38N E 510328; N 4004512), which encloses a large tell (c. 1.5 ha, c. $600 \mathrm{~m}$ altitude) that has been identified as the ancient city of Anisu known from the Neo-Assyrian texts (Lanfranchi 1995: 136). The Bora Plain, situated c. 3 km south-west of Qalat Dizeh, is an alluvial plain of about $75 \mathrm{~km}^{2}$, near the village of Nuraddin. The Bora Plain is bordered on the west by a crescent-shaped range of hills. These hills terminate by the river in the south, at the impressive mound known as Qalat-i Dinka (38N E 511927; N 3999160; c. $580 \mathrm{~m}$ altitude), about $500 \mathrm{~m}$ west of Gird-i Bazar (Fig. 2). The geology of the plain features Cretaceous period sedimentary rocks such as limestone, conglomerate, dolostone, and sandstone, as well as Quaternary period alluvium deposits along the Lower Zab. The mountains further to the east are characterised by bands of metamorphic and igneous rocks, particularly serpentinite and gabbro (Altaweel \& Marsh 2016: 23-24).

\subsection{The Peshdar Plain Project activities in the Bora Plain}

Since 2015, the Peshdar Plain Project, directed by Karen Radner (Ludwig-Maximilan University of Munich, LMU), has been conducting investigations in the Bora Plain to uncover the history and archaeology of this region with a particular focus on the Neo-Assyrian period (c. 900-600 BC). ${ }^{1}$ The project initially focused on

\footnotetext{
The Peshdar Plain Project has been conducted under the auspices of General Directorate of Antiquities of the Kurdish Autonomous
}

the two sites of Gird-i Bazar and Qalat-i Dinka. However, the results of the geoarchaeological trench, called GA42, opened in 2015 (Altaweel \& Marsh 2016) and the pottery surveys directed by Jessica Giraud ${ }^{2}$ in 2013 and 2015 in the area encompassing both Gird-i Bazar and Qalat-i Dinka (Giraud 2016), revealed that these two sites are, in fact, part of a large settlement of c. 60 ha, dubbed the Dinka Settlement Complex. The magnetic survey conducted from 2015-2017 by Jörg Fassbinder and his team confirmed these results (Fassbinder \& Ašandulesei 2016; Fassbinder et al. 2018), revealing a densely-built area in the lower town, that is between Gird-i Bazar and Qalat-i Dinka, with archaeological features interpreted as houses, courtyards, alleyways, public buildings, and workshops (Fig. 2). The first excavations started in autumn 2015 at Gird-i Bazar (Radner et al. 2016). Here, a chicken farm built in 2013 destroyed part of the mound, so between 2015 and 2017 the excavations concentrated on the undamaged section of the mound and extended into the undamaged area within the fenced-in enclosure. These excavations unearthed a series of buildings composed of rooms arranged around courtyards, and a large central open area where production activities took place (see below). The stone tools found during these three excavation seasons at Gird-i Bazar are the focus of this chapter.

The project's activities also targeted the rest of the lower town of the Dinka Settlement Complex. In the spring of 2017 a test trench, labelled DLT2, ${ }^{3}$ was opened about $200 \mathrm{~m}$ west of Gird-i Bazar (Fig. 2), where the magnetic survey had revealed three large free-standing buildings (Fassbinder et al. 2017). Here, among other things, a room with four large storage vessels was unearthed, which may indicate that this area was at least partially

Region of Iraq, the Sulaymaniyah Directorate of Antiquities and the Raparin Directorate of Antiquities. Funding has been made available to Karen Radner by the Alexander von Humboldt Foundation, the Ludwig-Maximilian University of Munich (LMU), and the Gerda Henkel Foundation. The 2015-2017 reports are downloadable for free from https://www.en.ag.geschichte.uni-muenchen.de/research/ peshdar-plain-project/index.html. Several scholars, specialists and $\mathrm{PhD}$ students from universities around the world have contributed to this project; for a complete list by year, see the reports.

2 Director of the Mission Archéologique Française du Gouvernorat de Soulaimaniah (MAFGS).

${ }^{3}$ DLT2 = Dinka Lower Town operation 2, with Gird-i Bazar intended as operation 1 . 


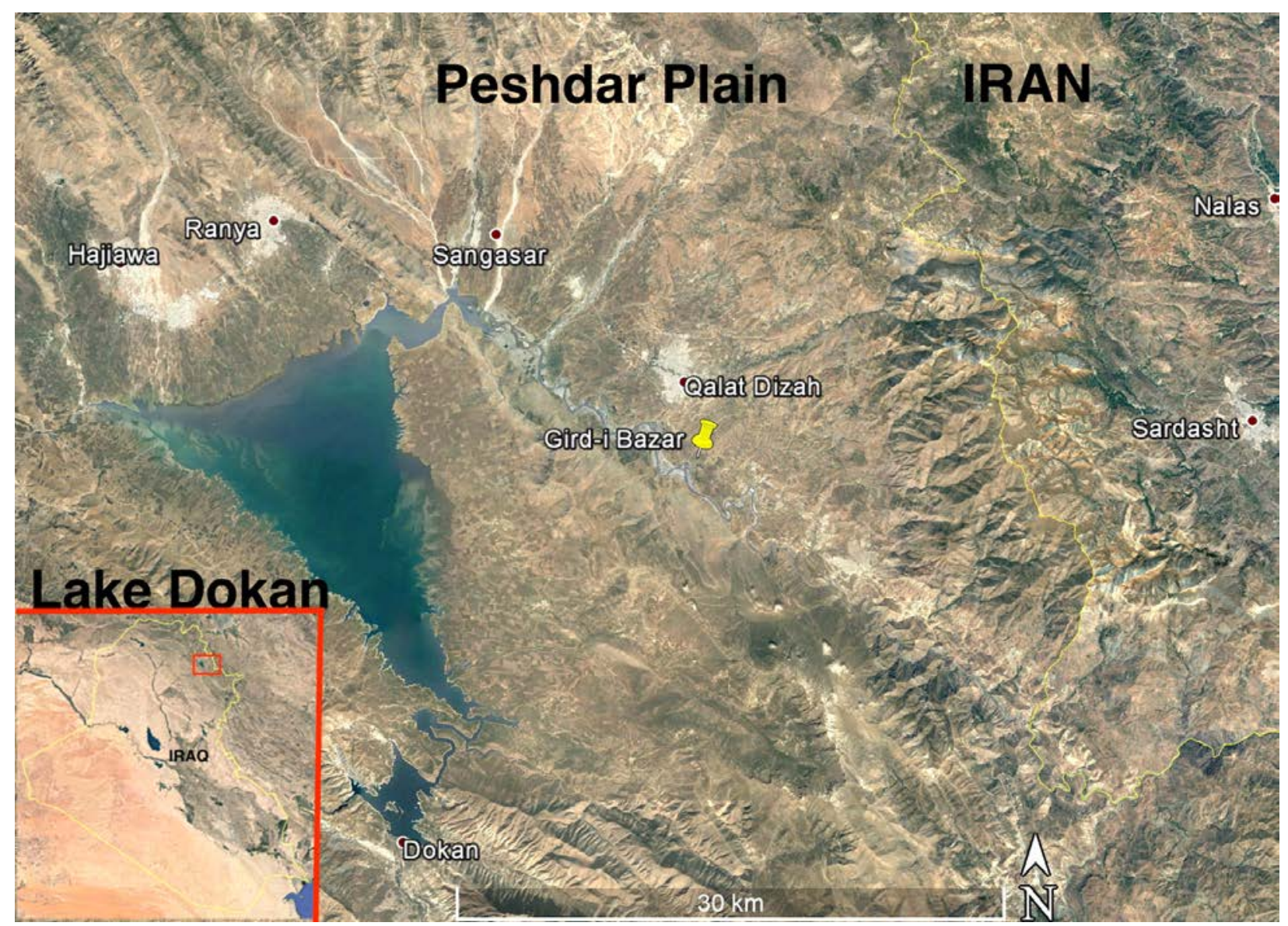

Figure 1. The location of Gitrd-i Bzaar in the Peshdar Plain. Inset: the location of the Peshdar Plain in Iraq. Source: Google Earth Satellite Image, accessed in August 2018.

used as a storage facility for the entire settlement (Radner et al. 2018). Finally, two campaigns in springs of 2016 and 2018 were undertaken on the western slope of Qalat-i Dinka, where large monumental and defensive structures were found, along with some luxury items (in ivory and Egyptian blue) and some iron arrowheads, indicating the presence of elites here; the publication of these results is expected in 2019.

\subsection{The chronology of the Dinka Settlement Complex}

The two pottery surveys mentioned above and the excavations have linked the main occupation of the settlement to the Iron Age chronological horizon.

In order to better establish this chronology, several samples (seeds, charcoal, teeth) were collected for ${ }^{14} \mathrm{C}$ analysis from the excavations at Gird-i Bazar, DLT2 and the geo-archaeological trench GA42 (Fig. 2). The results of these tests confirmed the Iron Age affiliation of the settlement, with calibrated (OxCal 4.2) date ranges spanning from c. 1200 to $790 \mathrm{calBC}$, and an outlier sample dated to 748-409 calBC, yielding a long range of possible dates due to the so-called 'Hallstatt plateau', a flat area in the radiocarbon graph affecting the dates between $800-400 \mathrm{BC}$ (for details about the ${ }^{14} \mathrm{C}$ analysis, see Radner 2018). The Iron Age structures can be observed to lie directly on the virgin soil (see below), so no earlier occupation is thought to be present in the excavated portions of the lower town.

During the Iron Age, a watershed moment for the Bora Plain, and the larger Peshdar Plain in which it is situated, was the annexation into the Assyrian Empire by the late 9th century BC, as mentioned above. A cuneiform tablet found by a farmer during agricultural work at Qalat-i Dinka in 2013 provided some clues about the history of the settlement under the Assyrians. This is a private sale document, dated to $725 \mathrm{BC}$, which mentions a subordinate of the Palace Herald as a witness (Radner 2015). The date falls under the reign of Shalmaneser V (r. 726-722 BC) and the reference to the Palace Herald indicates that the transaction happened within his sphere of authority, that is within the Province of the Palace Herald. This border march controlled by the Palace Herald had previously been only roughly located in the mountains east of Erbil; after the discovery of the tablet at Qalat-i Dinka it became clear that this province encompassed the area of the Peshdar Plain, possibly also including the Raniyah Plain (Radner 2016). Written sources inform us that this province was created during the reign of King 


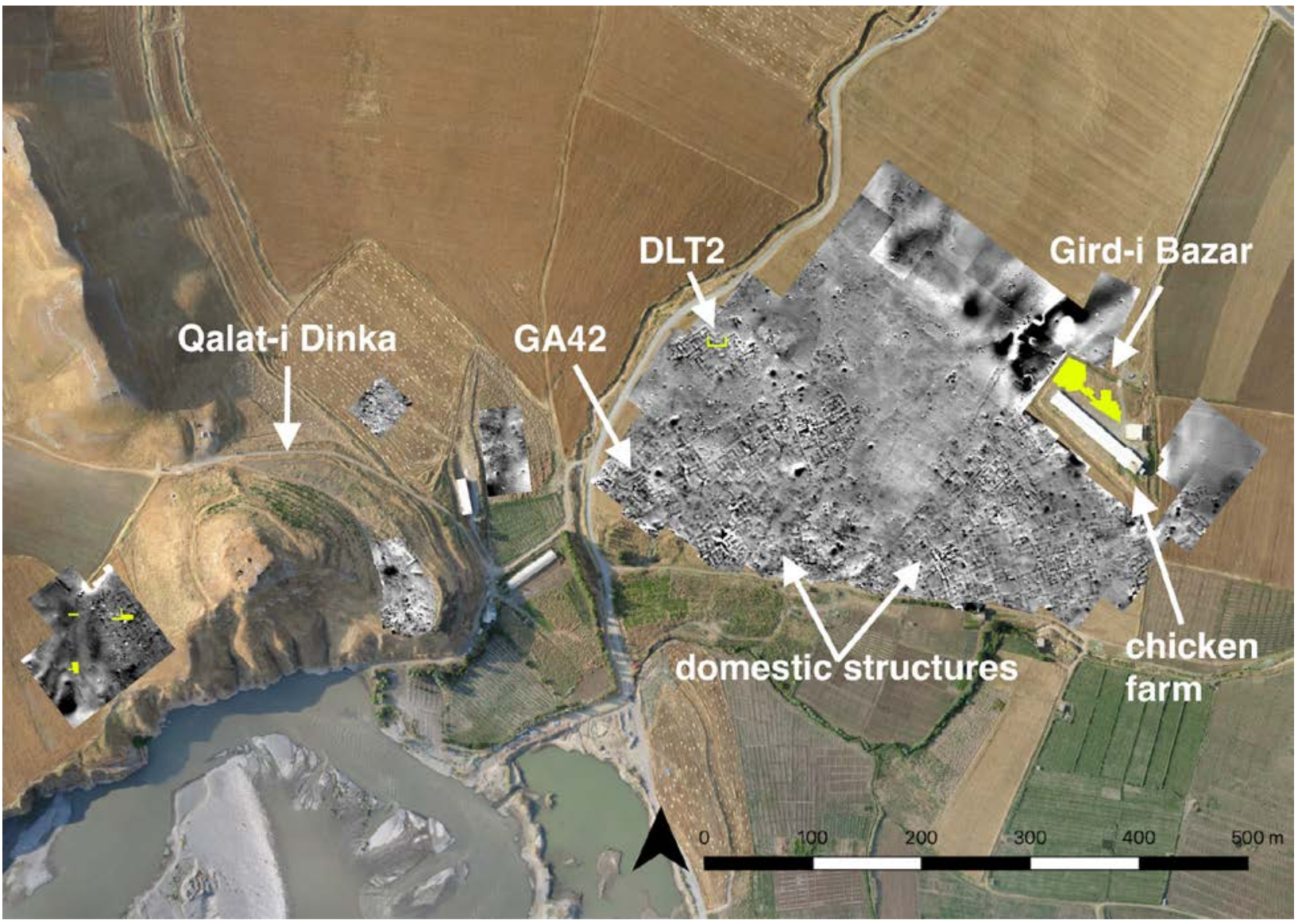

Figure 2. Drone image showing the excavations (in yellow) conducted by the Peshdar Plain Project in the Bora Plain overlying J. Fassbinder's megnetogram of the lower town of the Dinka Settlement Complex.

Drone image by ICONEM (Paris), courtesy of Un Film à la Patte (Strasbourg) and Jessica Giraud.

Shalmaneser III (r. 859-824 BC) in the late 9th century $\mathrm{BC}$ to secure Assyrian control of the eastern border of the empire. This border lay in close proximity to the kingdom of Mannea, located on the other side of the Zagros chain, and the buffer state of Hubuškia, possibly located in the plain of Sardasht, today in Iran, about 30 kilometres east of the Bora Plain (Radner 2016: 21). Both of these kingdoms had 'on again, off again' periods of alliance and rivalry with the Assyrian Empire. Based on the Assyrian royal correspondence, it seems that by the time of Esarhaddon (r. $681-669 \mathrm{BC}$ ) the political situation on the Peshdar Plain had become highly unstable, and the relationship between the Assyrian Empire and the kingdoms of Mannea and Hubuškia soured, leading us to suspect that the Assyrians had lost control over the plain during the course of the 7th century BC (Radner 2016: 21).

Combining the current ${ }^{14} \mathrm{C}$ date ranges and the written sources, it can be concluded that the Dinka Settlement Complex had been founded before the Assyrians' arrival, and continued its life under the empire until some point during the 7th century BC. Determining the contribution of the Assyrians to the settlement (e.g., architectural modifications, material culture changes, economic and administrative interventions) is currently one of the main focuses of the project. Surely, the settlement, after its annexation by the Assyrians, must have had a crucial strategic role in controlling the Lower Zab river, as well as the passage through the Zagros Mountains into western Iran.

The excavations at the Dinka Settlement Complex provide us the opportunity to cast light onto this eastern province of the Assyrian Empire, about which so far little is known archaeologically. Moreover, it can potentially help to synchronise Western Iranian material culture (particularly pottery) with the Assyrian material from within the heartland, due to its connection to both areas.

\section{Overview of the archaeological investigations at Gird-i Bazar, 2015-2017}

The excavation area of Gird-i Bazar (Fig. 3) extends within the metal fence surrounding the chicken farm by about $700 \mathrm{~m}^{2}$. The excavations revealed some modern

\footnotetext{
4 This section draws on the excavation results of the 2015-2017 campaigns. For details see the excavation reports: Radner et al. 2016; $2017 ; 2018$
} 


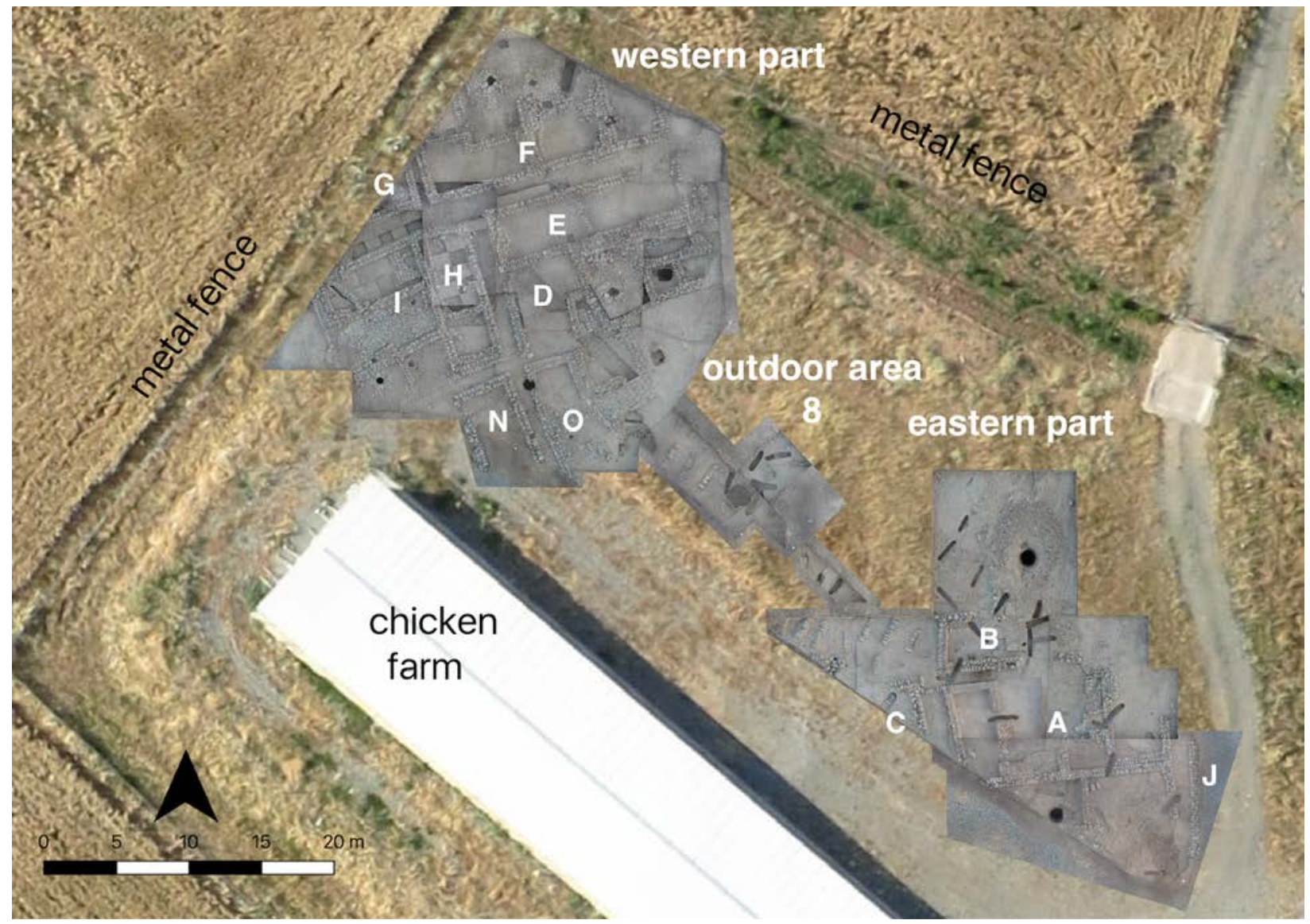

Figure 3. Drone image by ICONEM (courtesy of Un Film à la Patte (Strasbourg) and Jessica Giraud) overlaid by the orthophoto prepared by Andrea Squitieri showing the 2015-2017 excavated areas at Gird-i Bazar. The letters indicate the building names.

disturbances as well as several Sasanian period graves, ${ }^{5}$ both of which caused damage to the Iron Age structures below. Both the graves and the modern structures reused the cobblestones from which the Iron Age walls were built.

Excavations in the eastern part unearthed two buildings called A and B, the former composed of rooms disposed around the central Courtyard 2, and two alleys (alley 4 and 25) separating Buildings A and B from Buildings $C$ on the west and $J$ on the east, the latter two only partially preserved. The main feature of this area is a deep well located north of Building B and excavated to a depth of about $7 \mathrm{~m}$ which yielded large quantities of pottery sherds and animal bones. This well may have been part of an extensive water management system whose remains are still visible east of Gird-i Bazar, in the form of vertical shafts leading to underground channels (qanat). Apart from pottery sherds, the rooms of these two buildings were quite devoid of objects. Unfortunately, this section of Gird-i Bazar was heavily damaged by both several Sasanian graves and modern

\footnotetext{
${ }^{5}$ The chronology of the Sasanian graves was established by ${ }^{14} \mathrm{C}$ analysis, as well as through comparative analysis of some of the grave goods, see Greenfield 2017; Downey 2018.
}

pits and installations (in which coins belonging to the Saddam era were found). Moreover, the construction of the chicken farm irremediably destroyed some of the ancient structures, in particular most of Buildings $C$ and J.

In the western part of Gird-i Bazar, the ancient structures have been better preserved because no Sasanian grave had been installed here and the modern disturbances were much less invasive than in the eastern part. Buildings D, E, F, G, H, I, N and O were unearthed in this area. Circulation between them was granted by two long alleys, 12 and 13, which ran almost perpendicular to each other As in the eastern part, buildings are composed of rooms arranged around courtyards equipped with paved stone floors.

Several features were found in this area. In Building $G$, a floor made of stone slabs with many traces of burning and ash is evidence for the existence of a cooking installation. On the stone slabs, a stone pounder was found.

A well was found in the courtyard of Building F. A socket stone sunk into the ground was found next to this well. 
This installation may have served to support a vertical wooden pole forming a mechanism (Arab: shaduf) designed to collect water from the adjacent well. Also in this courtyard two ovens were found, surrounded by many cooking pot sherds. From the courtyard of Building F a drain starts which ends in Alley 13, to the south. This drain is made of a row of stones covering the channel below and was intended to drain waste water from the courtyard into the alley.

Building D had a stone paved courtyard in which a well was found, and a drain running northwards towards Alley 13. Moreover, a large pottery kiln, cut into the bedrock, was unearthed in a room of this building. It was filled with the collapse from the upper structure. It was a vertical kiln with an upper chamber and a combustion chamber below separated by an (unpreserved) kiln floor.
Building I has also yielded evidence for the location of a pottery workplace. Next to a stone workbench located in Room 46, a pivoted stone of the type used for a potter's slow- wheel was unearthed, (see below). An additional drain was found in this room, which also ran in the direction of Alley 13 to the north. To the south of Room 46 lay a paved stone courtyard, whose floor was covered with clusters of fragmented pottery vessels as well as many stone tools. This courtyard may have been utilised for the production of pottery too. To the south, another well was found, in addition to two badly preserved ovens surrounded by many pottery fragments.

In between the eastern and the western sections, a large open area dubbed Outdoor Area 8 was excavated. This area was equipped with a pottery kiln similar to that found in Building D and described above, and
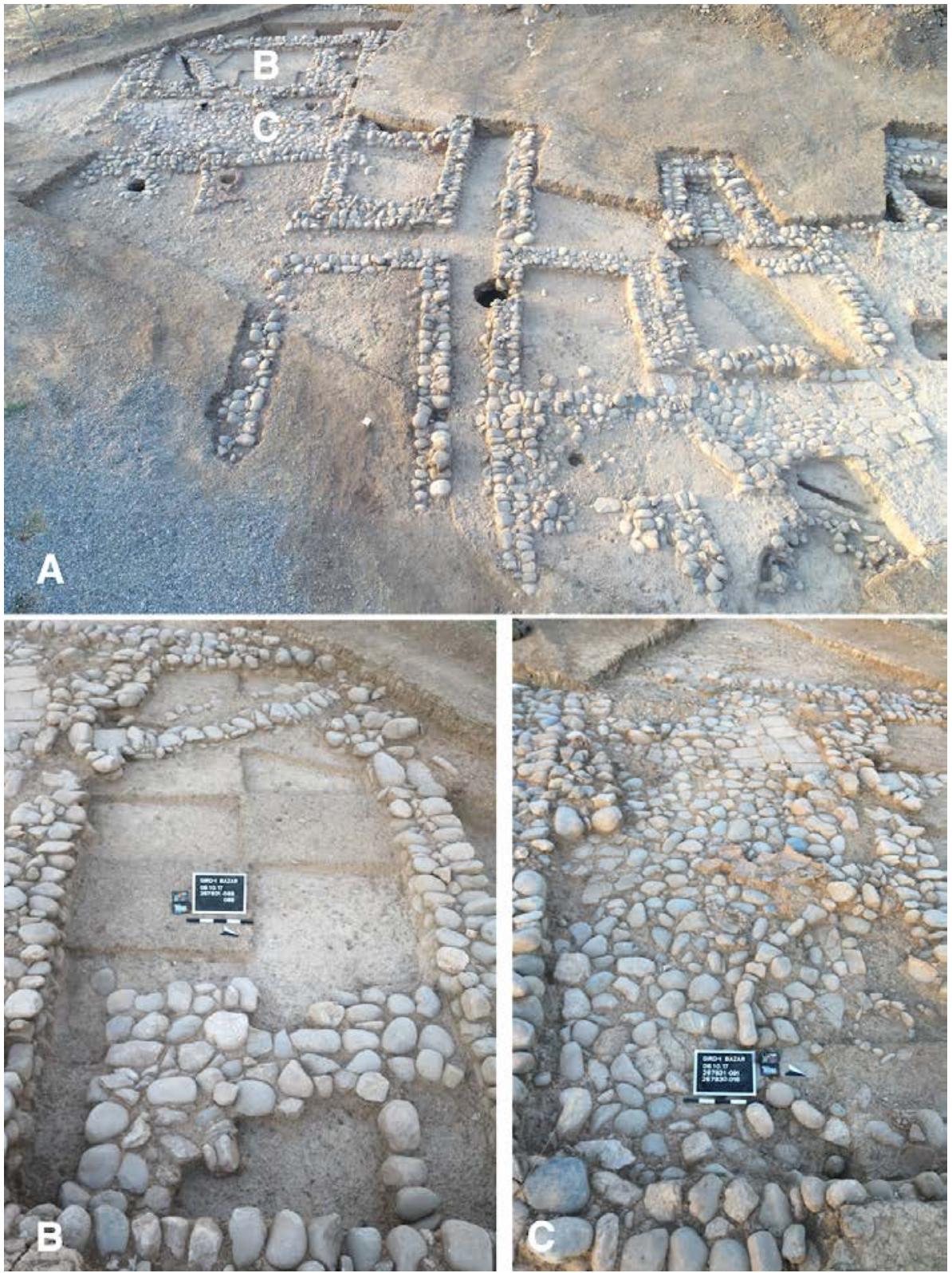

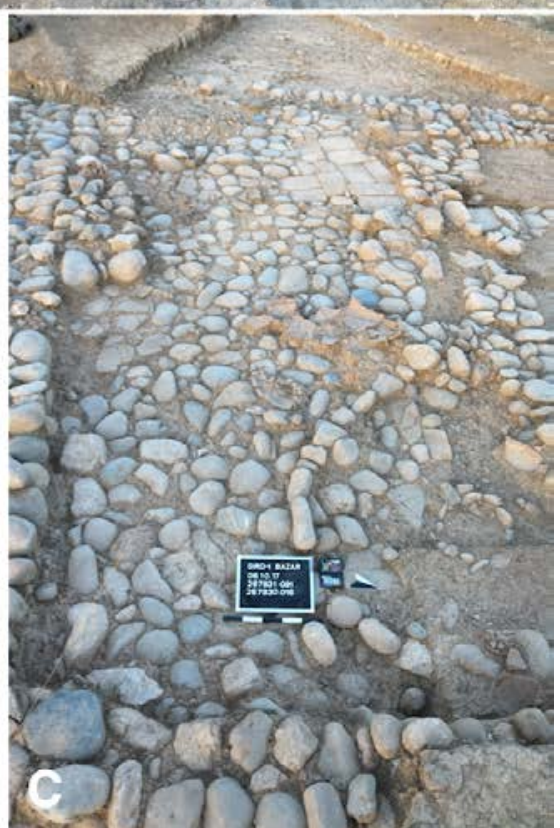

Figure 4. A. The western part of the excavated area at Gird-i Bazar. B: Room 46 where the pivoted stone for the potter's slow-wheel was found; C: Courtyard 18 where a large amount of smashed pottery vessels and stone tools was found. Photos by Andrea Squitieri and Peter Bartl. 
three pyrotechnical installations, of which one had been severely damaged by a modern pit (Fig. 4). Analyses are ongoing to determine what kind of activities these pyrotechnical installations were used for, but their presence together, with the pottery kiln, indicates this area was most likely utilised for pottery production.

The archaeological features excavated in Gird-i Bazar seem to indicate the existence of a workshop dedicated to pottery production, likely serving the entire settlement. The water management facilities may have also supported this industrial activity by providing enough water for preparing the clay, whereas the ovens and cooking installations indicate that people only occasionally consumed food in this workshop area (though it is not clear whether food was also processed here, see below). Overall, apart from pottery sherds, the density of finds is not very high throughout Gird-i Bazar, and some rooms were found that were completely devoid of any small objects. Stone tools were mostly found on the floors, or within room and pit fills, although a few also came from the topsoil.

\section{The stone tool assemblage of Gird-i Bazar}

\subsection{Typology and main characteristics}

As mentioned above (and pottery sherds excluded), the stone tools from Gird-i Bazar constitute the majority of finds excavated during the 2015-2017 campaigns, with 87 examples out of 122 total finds (71\%) belonging the Iron Age period. Full reports of the stone tools and the other finds are available in Barbanes Wilkinson et al. 2016; Squitieri 2017, and Squitieri 2018. The sections below offer details about the stone tool typology and distribution to determine their function. Gird-i Bazar stone tools are divided into six main categories: pebble mortars, pounders, polishers, pounders/polishers, spherical tools, and perforated stones. A seventh category ('miscellanea') groups together other tool types that occurred only once at the site. The typological classification derives from the work of $\mathrm{K}$. Wright and D. Eitam (Wright 1992; Eitam 2009). It is based on the tools' morphology enriched by observations about wear marks and raw materials.

\subsubsection{Pebble mortars (Fig. 5)}

Pebble mortars, also called pebble cupmarks, are flattish disc-shaped pebbles with one, or more commonly, two shallow rounded depressions in the middle of the two opposite sides. In most cases, the bodies of these objects are unworked or they show only a few pecking marks on

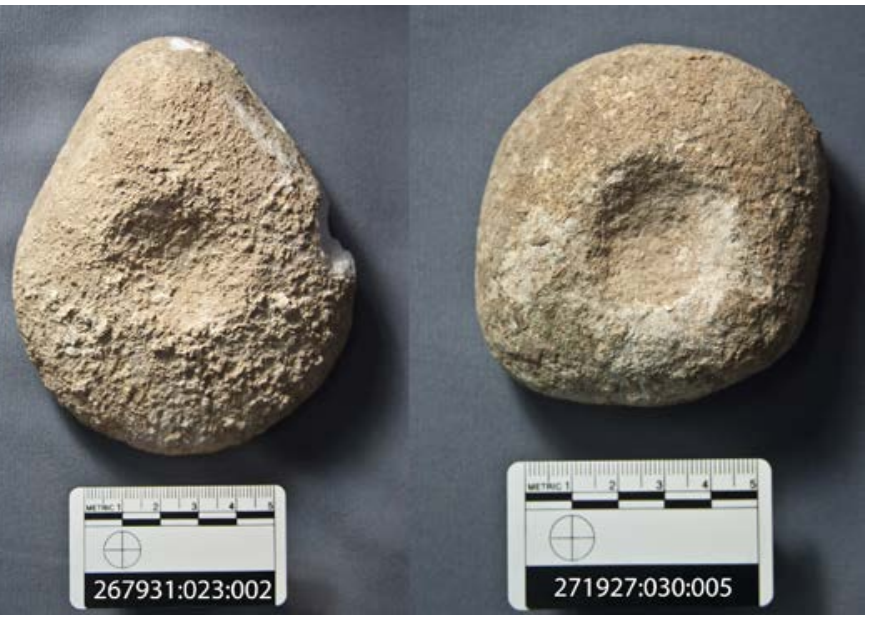

Figure 5. Pebble mortars from Gird-i Bazar. Photo by Peter Bartl.

the rounded edges, indicating they were roughly cut-toshape. Their size can vary from small examples of about $6 \mathrm{~cm}$ in diameter to larger ones reaching about $20 \mathrm{~cm}$ in diameter. Their size makes them portable tools. The two shallow depressions in the middle of their body are usually around $2 \mathrm{~cm}$ deep and $4 \mathrm{~cm}$ in diameter, and show pecking marks indicating that they were subject to percussive force. It is likely they were employed to crush small materials, such as minerals. These tools demonstrate an expedient design; that is, they did not require a time-consuming, highly intensive labour for their manufacture. Indeed, they seem to have been river pebbles that were collected from the nearby river and used as tools. Their raw material is a white variety of limestone, usually covered by a 2-3 mm thick brown lime-coat deriving from post-depositional processes. This stone is hard enough to withstand impact with small substances. Limestone, however, has a hardness of approximately 3 on the Mohs scale meaning that it may produce grit under strong, repetitive, percussive force. This makes it less likely that these tools were used to crush small edible substances such as seeds or herbs as these would have been contaminated with limestone debris. It is therefore more likely that these tools were used to crush non-edible substances such as minerals (see below).

\subsubsection{Pounders (Fig. 6)}

Pounders are sub-spherical pebbles that fit nicely into the palm of a hand, In many cases they have pecking marks on their body, indicating they were used to crush or pound. Their source material can be limestone, but examples made of harder igneous stones such as basalt are also attested. Like the pebble mortars, they are expedient tools - river pebbles that were collected for use as tools. Their size oscillates between 5 and $7 \mathrm{~cm}$ in diameter. It is their size that distinguishes them from the smaller spherical tools that were possibly used as weights (see below). 


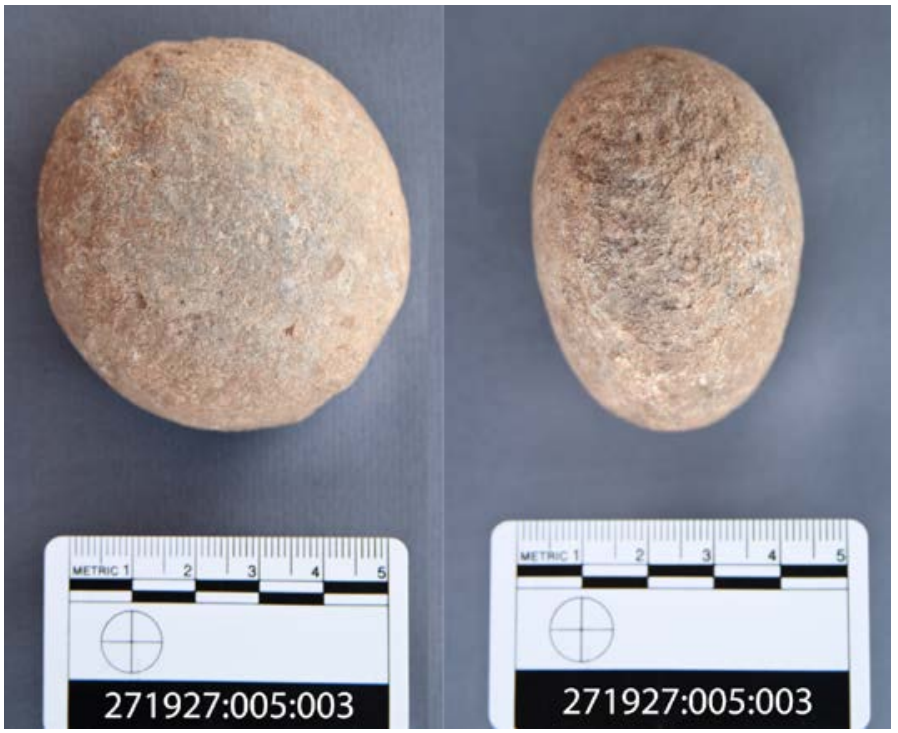

Figure 6. Pounder from Gird-i Bazar. Photo by Peter Bartl.

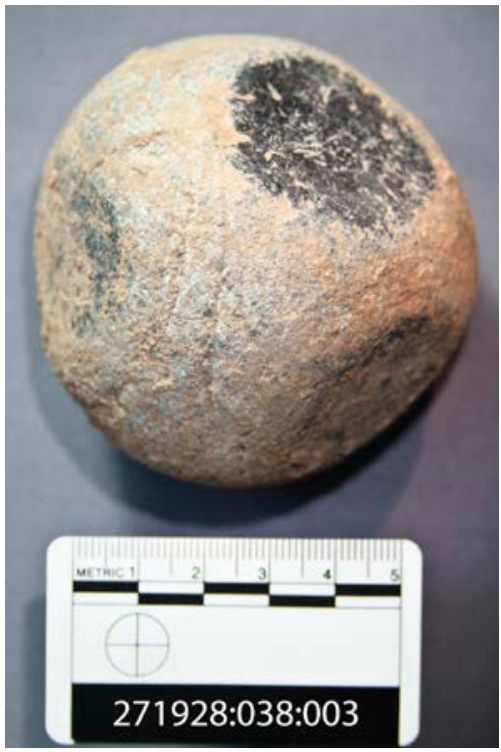

Figure 7. Polisher from Gird-i Bazar. Photo by Peter Bartl.

\subsubsection{Polishers (Fig. 7)}

Polishers are sub-spherical pebbles having one, two, or in some cases three, very flat and shiny faces, which clearly distinguishes them from pounders. There are some cuboid polishers with four flat faces. Their size is very similar to that of pounders. As with the pounders, these tools are also expedient devices collected from the river as simple pebbles. That the raw materials were intentionally selected is evident because polishers, unlike pounders and pebble mortars, are in most cases made out of a hard igneous or metamorphic rock, such as basalt (Mohs $=7$ ), granite (Mohs= 7) or serpentinite (Mohs = 6).

\subsubsection{Pounders/polishers (Fig. 8)}

These are multi-use tools that have the same diagnostic characteristics as both pounders (pecking marks) and polishers (very flat and shiny faces), indicating that they were used for both functions at some point during their life-cycle. The pecking marks are concentrated on the regions outside the flat faces, indicating that these tools were intended originally as polishers and were then reused as pounders.

\subsubsection{Spherical tools: weights (Fig. 9)}

These are small spherical or oval pebbles, weighting between $100-200 \mathrm{~g}$, with a diameter of $5 \mathrm{~cm}$ or less, which do not show pecking marks and are too small to comfortably fit in the palm of a hand to be used for crushing or pounding. For this reason, they are interpreted as weights in the present classification. Unfortunately, their context does not help to determine their function as they were not found in clusters, for example, and they were not found in sufficient quantity to detect patterns in their weight distribution. These tools share with all the other tools their expedient design.

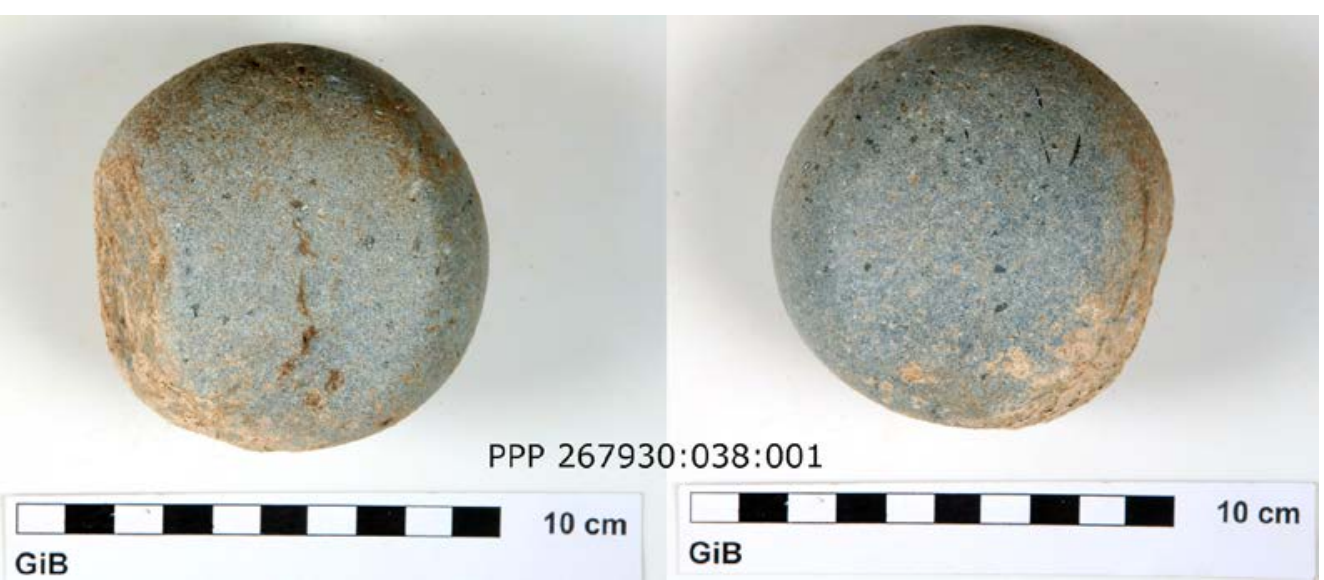

Figure 8. A pounder/ polisher from Gird-i Bazar. Photo by Andrea Squitieri. 


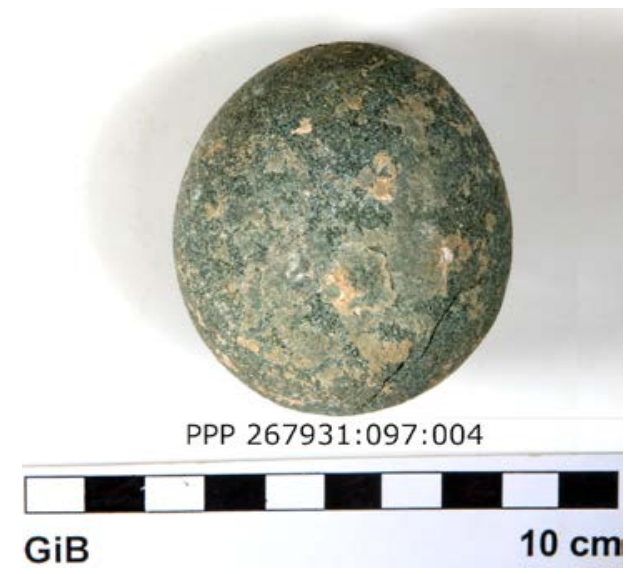

Figure 9. A weight from Gird-i Bazar. Photo by Andrea Squitieri.

\subsubsection{Perforated stones (Fig. 10)}

Perforated stones are circular tools roughly cut to shape with a circular perforation in the centre. Their diameters range between 10 and $15 \mathrm{~cm}$. The perforation, with a diameter of about 3-4 cm, has a bi-conic section indicating it was perforated from opposite sides and not drilled through. The weight of these objects varies from about $0.5 \mathrm{~kg}$ to about $2 \mathrm{~kg}$. Raw material commonly used for these stones was limestone. The purpose of these tools is not well understood. Similar perforated stones were quite common in the Near Eastern stone tool repertoire from prehistoric times onwards. Various theories for their use have been offered in the literature include: weights for hammers, lathe fly-wheels, postsockets, net-weights, or weights for digging sticks which were mounted on ploughs to help loosen the soil (see Squitieri 2017: 156-7 and bibliography therein).

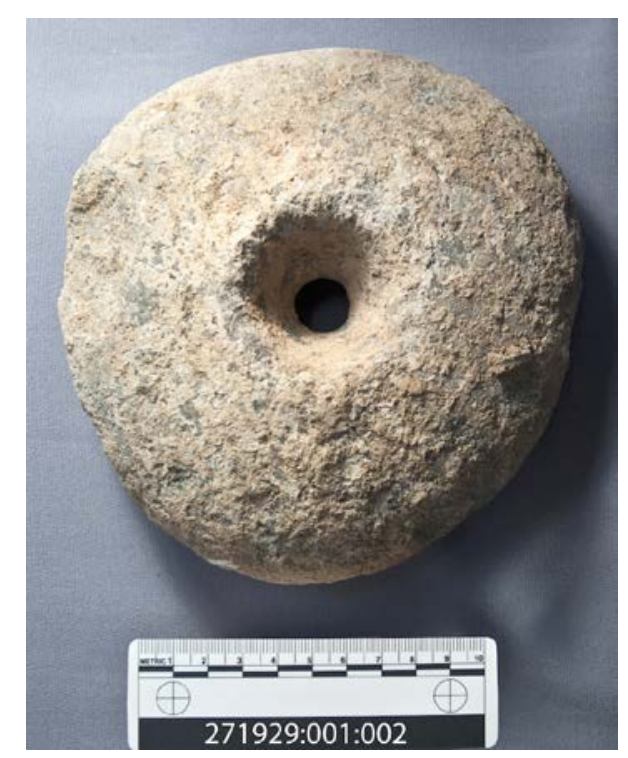

Figure 10. A perforated stone from Gird-i Bazar. Photo by Andrea Squitieri.
None of these interpretations can be taken as definitive, and the Gird-i Bazar examples do not help to establish their function because in most cases they come from topsoil or room fills, nor do they show diagnostic wear marks. Their rare occurrence on floors, however, may hint at their use in combination with ploughs because one would assume that in this case they would have been mainly used and discarded in open fields rather than within rooms.

\subsubsection{Miscellanea}

I have grouped three tools that have each occurred once into this category. The first two are a broken whetstone (length $8.5 \mathrm{~cm}$ ) and an elongated pestle (length $9.5 \mathrm{~cm}$ ). Whetstones are usually employed to sharpen other objects such as arrows or blades; pestles are connected to pounding actions usually in association with mortars. The very rare occurrence of these two tools at Gird-i Bazar indicates that the activities associated with these types of tools occurred only rarely, at least in the excavated areas of the site.

The third tool is a pivoted stone (Fig. 11). This is a rounded object (diam. $18 \mathrm{~cm}$; height $15 \mathrm{~cm}$ ) showing a flat surface in the middle of which a conical pivot $4.5 \mathrm{~cm}$ high protrudes. The surface of both the flat face and the pivot is smooth and shiny. The opposite side of the object is slightly rounded. Due to its shape, this pivoted stone is interpreted as the upper-bearing of a potter's slow-wheel. It was used in conjunction with a socketed stone (with a socket in the centre in which the pivot could be inserted). Such a socketed stone was not found in connection with the present pivoted stone, but similar objects may have been easily reused as door sockets, which do occur at Gird-i Bazar. By keeping the socketed stone still, the pivoted stone could be moved to generate momentum. On the top of the pivoted stone, a wheel-head in clay or wood could be attached by using bitumen or clay. On top of this wheel, the lump of clay was fashioned by the potter. The potter could rotate the wheel-head by hand or by using a stick (Squitieri 2018). Several pivoted and socketed stones have been found in the Near East and Egypt in both Bronze and Iron Age sites, and ethnographic observations have helped to reconstruct their use (Duistermaat 2008: 147; Powell 1995). At Gird-i Bazar this tool was found upside down near the bench installation in Room 46 (see above). It is yet more evidence that supports our interpretation of Gird-i Bazar as a pottery production centre and it casts light on the specific technique used to make pottery, namely the slow-wheel technique. This interpretation matches the results from both microscopic and macroscopic analyses conducted on the Gird-i Bazar pottery, which indicated the use of a slow-wheel for fashioning the pots (Amicone 2017; Herr 2017). 


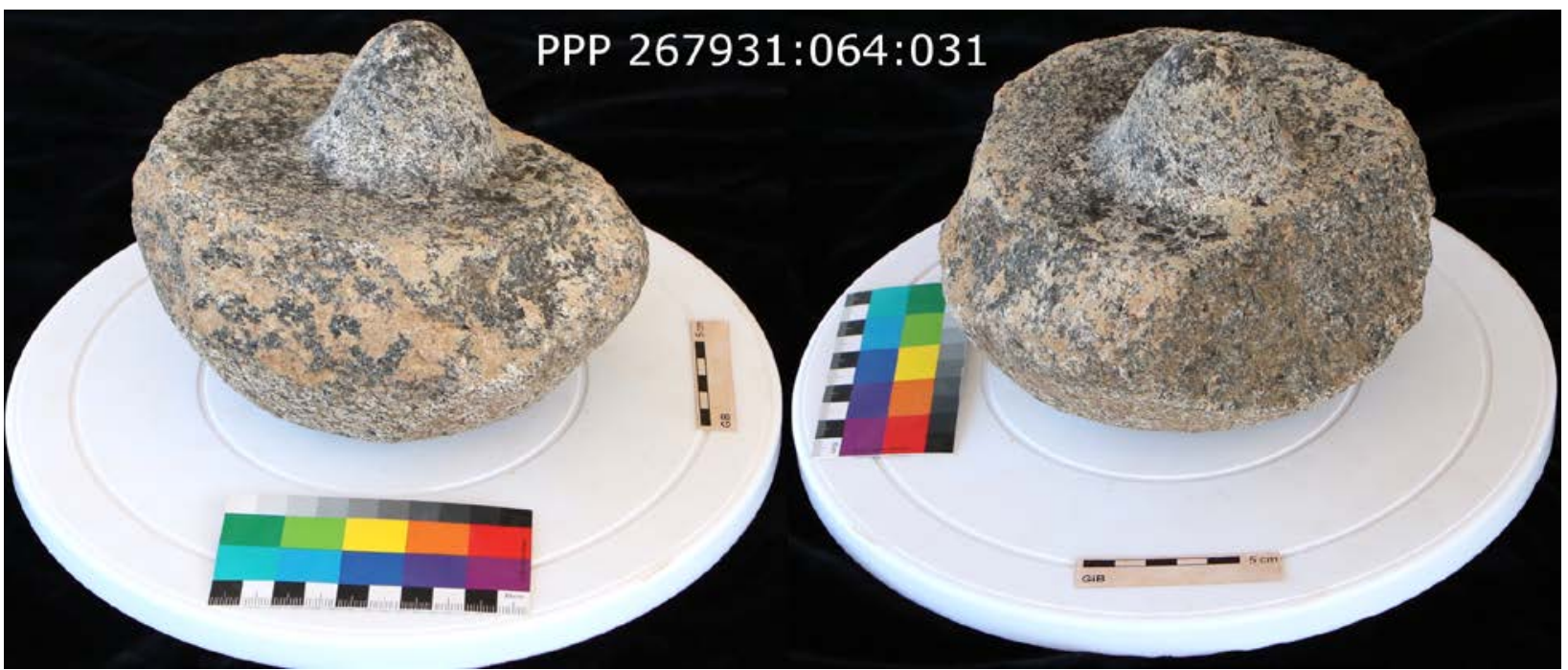

Figure 11. The pivoted stone found at Gird-i Bazar used in combination wi ${ }^{\mathrm{L1} \ldots}$ socketed stone for a potter's slow-wheel. Photo by Andrea Squitieri.

\subsection{General characteristics and function of the tools}

Overall, the stone tools from Gird-i Bazar represent a group of utilitarian, portable, and expedient design objects suitable for everyday production activities. The range of raw materials found in these objects betrays a local origin, most likely the river bed. There is no evidence for imported material. The extensive use of the local white limestone for these tools is not an ideal choice if one considers that this rock is not very hard and can be quickly damaged and worn out through use; however, its ready availability coupled with the minimal effort put into the tools' manufacture counterbalanced this problem by allowing cheap and frequent tool replacement.

What is striking is the absence of large groundstone tools such as mortars, mortar bowls, tripod mortars, pestles (with only one exception), grinding stones, querns, and handstones, all primarily used for crushing and pounding food. Despite the fact that food was consumed at Gird-i Bazar, as evidenced by the presence of the ovens, it seems that it was processed elsewhere. A possibility is that, of course, the large groundstone tools were removed upon the abandonment of the site. It is worth mentioning also the possibility that the grinding tools such as mortars were made of wood, a raw material that did not need to be imported from far, which, however, would not survive in the archaeological record. Nevertheless, the idea that food was not processed at Gird-i Bazar accords with the general interpretation of the site as a large pottery production centre (as suggested by the presence of the pottery kilns and the pivoted stone for a potter's wheel), in which people principally worked to produce pottery over other production activities related to food. Due to this general function of the site, it is likely that the stone tools found in it were related to pottery production. The pebble mortars together with the pounders described above may have been used to crush minerals used as a temper. Petrographic analysis has confirmed the presence of such minerals in the pottery fabric showing angular edges, indicating that they had been crushed before being mixed into the clay (Amicone 2017). As previously discussed, pebble mortars would not have been suitable for crushing edible materials, such as seeds, because of the likelihood of contamination. The polishers from Gird-i Bazar may also have been used at the final stage of pottery production to finish the vessels, or for burnishing the pot's surface, as many vessels show burnishing marks (Herr 2017). Finally, small weights and perforated stones are not clearly associated with pottery production but they may have had a role that, at the moment, is difficult to understand.

\subsection{Distribution analysis}

Due to the role of Gird-i Bazar as a workshop area serving the entire settlement for pottery products, the analysis of the stone tool distribution on floors can give us some insights about the intensity and distribution of these production activities. The distribution analysis shown in Fig. 12 has only been applied to objects found on the floors of the western part of Gird-i Bazar because these floors were only slightly affected by the Sasanian era interments or by modern activity. Consequently, this area has yielded by far the highest number of objects during the three excavation campaigns. Fig. 12 shows that the distribution of objects in the western part of Gird-i Bazar is rather uneven, with some architectural units particularly rich in items, whereas others appear to be almost empty. Most of the items were concentrated in open areas; courtyards are generally richer in objects 


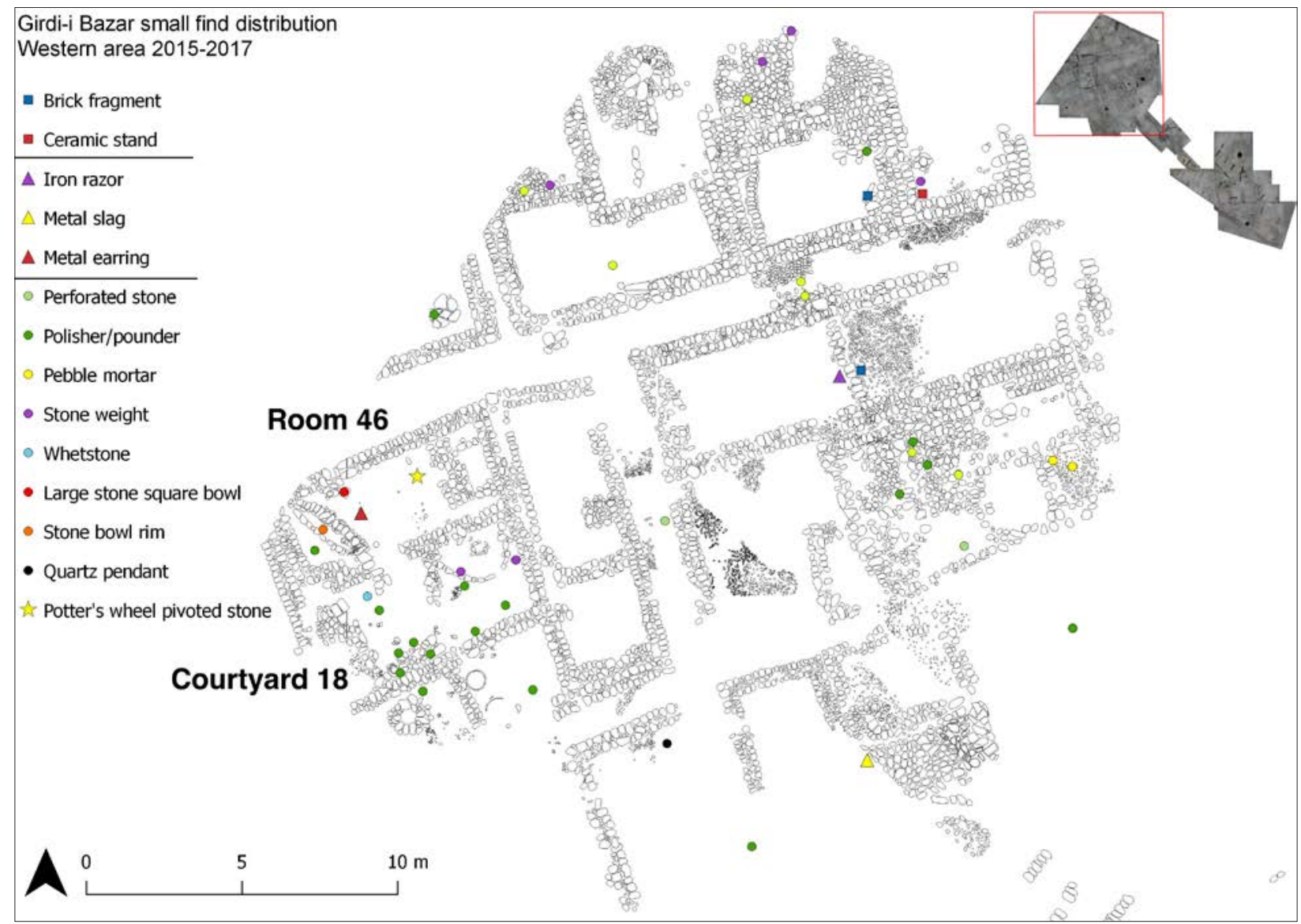

Figure 12. Distribution map of the small finds from western part of Gird-i Bazar. Prepared by Andrea Squitieri.

than rooms (20 vs 15 items). Most of the stone tools were collected from the floor of Courtyard 18, situated next to Room 46 where the pivoted stone was found and therefore at least one of the pottery workplaces was located. This observation strengthens the connection between stone tools and pottery production at Gird-i Bazar as these two units were evidently used for intensive production, linked to pottery making, thus creating a concentration of stone tools. The units where no stone tools (and no other small objects) were found were possibly used for activities that did not leave a visible mark in archaeological record, perhaps because they used perishable objects.

\section{Conclusions}

The excavations by the Peshdar Plain Project in the Bora Plain have started to reveal a large urbanised settlement, the Dinka Settlement Complex, founded in the beginning of the Iron Age and annexed into the Assyrian Empire sometime during the late 9th century BC. Its location next to the Zagros mountain chain, the border between the Empire and the states of Mannea and Hubuškia, makes it a privileged standpoint from which to study the cultural and economic relations between the local communities and both the Assyrians and the Iranian states beyond the border. The excavations conducted so far have only begun to unearth a complex urbanised settlement, composed of different functional areas, in which Gird-i Bazar was a large pottery workshop serving the entire community. This chapter presented the stone tool repertoire from Gird-i Bazar. These represent a group of small, portable tools expediently designed out of locally available raw materials. They were much more likely used in connection to pottery production, which was the main industry characterising Gird-i Bazar. The notable absence of other types of groundstone tools that could be linked to food processing may be the consequence of this activity happening elsewhere, or of a specific abandonment process. Perhaps large groundstone tools were deemed more valuable and durable than the tools left behind at Gird-i Bazar that thus entered the archaeological record. Future research will clarify this point. The Gird-i Bazar stone tool assemblage seems therefore to be functionally specialised and it offers a good reference point for other Iron Age stone tool assemblages whose functions were linked to nonfood, industrial productions. 


\section{Bibliography}

Altaweel, M. \& Marsh, A. 2016. Landscape and Geoarchaeology in the Bora Plain. In: Radner, K., Kreppner, F. J., Squitieri, A. (eds) 2016. Exploring the Neo-Assyrian Frontier with Western Iran. The 2015 Season at Gird-i Bazar and Qalat-i Dinka. Gladbeck: PeWe-Verlag: 23-28.

Amicone, S. 2017. Petrographic Analysis of the 20152016 pottery from Gird-i Bazar. In: Radner, K., Kreppner, F. J., Squitieri, A. (eds) 2017. Unearthing the Dinka Settlement Complex.The 2016 Season at Gird-i Bazar and Qalat-i Dinka. Gladbeck: PeWe-Verlag: 128-137.

Downey, K. 2018. The Sasanian Cemetery of Gird-i Bazar. In: Radner, K., Kreppner, F. J., Squitieri, A. (eds) 2018. The Dinka Settlement Complex 2017. The Final Season at Gird-i Bazar and First Work in the Lower Town. Gladbeck: PeWe-Verlag: 173-184.

Duistermaat, K. 2008. Pots and Potters of Assyria: Technology and Organization of Production, Ceramic Sequence and Vessel Function at Late Bronze Age Tell Sabi Abyad, Syria, Turnhout: Brepols Publishers.

Eitam, D. 2009. Late Epipalaeolithic Rock-Cut Installations and Ground Stone Tools in the Southern Levant: Methodology and Classification System. Paléorient 35: 77-104.

Fassbinder, J. \& Ašandulesei, A. 2016. The Magnetometer Survey of Qalat-i Dinka and Gird-i Bazar, 2015. In: Radner, K., Kreppner, F. J., Squitieri, A. (eds) 2016. Exploring the Neo-Assyrian Frontier with Western Iran. The 2015 Season at Gird-i Bazar and Qalat-i Dinka. Gladbeck: PeWe-Verlag: 36-38.

Fassbinder, J., Ašandulesei, A. \& Scheiblecker, M. 2017. Magnetometer Prospection in the Dinka Settlement Complex. In: Radner, K., Kreppner, F. J., Squitieri, A. (eds) 2017. Unearthing the Dinka Settlement Complex. The 2016 Season at Gird-i Bazar and Qalat-i Dinka. Gladbeck: PeWe-Verlag: 18-28.

Fassbinder, J., Ašandulesei, A. \& Scheiblecker, M. 2018. The 2017 Magnetometer Survey of the Dinka Settlement Complex. In: Radner, K., Kreppner, F. J., Squitieri, A. (eds) 2018. The Dinka Settlement Complex 2017. The Final Season at Gird-i Bazar and First Work in the Lower Town. Gladbeck: PeWe-Verlag: 20-23.

Giraud, J. 2016. Surface Survey of the Dinka Settlement Complex, 2013-2015. In: Radner, K., Kreppner, F. J., Squitieri, A. (eds) 2016. Exploring the Neo-Assyrian Frontier with Western Iran. The 2015 Season at Gird-i Bazar and Qalat-i Dinka. Gladbeck: PeWe-Verlag: 2935.

Greenfield, T. 2017. Bioarchaeological Research at Gird-i Bazar, 2016. In: Radner, K., Kreppner, F. J., Squitieri, A. (eds) 2017. Unearthing the Dinka Settlement Complex. The 2016 Season at Gird-i Bazar and Qalat-i Dinka. Gladbeck: PeWe-Verlag: 168-171.
Herr, J.-J. 2017. The 2016 Season Pottery and a First Catalogue of the Chaines Operatoires at Gird-i Bazar. In: Radner, K., Kreppner, F. J., Squitieri, A. (eds) 2017. Unearthing the Dinka Settlement Complex.The 2016 Season at Gird-i Bazar and Qalat-i Dinka. Gladbeck: PeWe-Verlag: 104-127.

Lanfranchi, G. B. 1995. Assyrian Geography and NeoAssyrian Letters: the Location of Hubushkia again. In: Liverani, M. (ed.), Neo-Assyrian Geography, Rome: Università La Sapienza: 127-137.

Powell, C. 1995. The nature and use of ancient Egyptian potter's wheels. In: Kemp, B. J. (ed.), Amarna Reports VI, London: Egyptian Exploration Society: 309-335.

Radner, K. 2015. A Neo-Assyrian Slave Sale Contract of 725 BC from the Peshdar Plain and the location of the Place Herald's Province. Zeitschrift für Assyriologie und Voderasiatische Archäologie 105: 192-197.

Radner, K. 2016. The Peshdar Plain in the Neo-Assyrian Period: the Border March of the Palace Herald. In: Radner, K., Kreppner, F. J., Squitieri, A. (eds) 2016. Exploring the Neo-Assyrian Frontier with Western Iran. The 2015 Season at Gird-i Bazar and Qalat-i Dinka. Gladbeck: PeWe-Verlag: 17-22.

Radner, K., Kreppner, F. J., Squitieri, A. (eds) 2016. Exploring the Neo-Assyrian Frontier with Western Iran. The 2015 Season at Gird-i Bazar and Qalat-i Dinka. Gladbeck: PeWe-Verlag.

Radner, K., Kreppner, F. J., Squitieri, A. (eds) 2017. Unearthing the Dinka Settlement Complex.The 2016 Season at Gird-i Bazar and Qalat-i Dinka. Gladbeck: PeWe-Verlag.

Radner, K., Kreppner, F. J., Squitieri, A. (eds) 2018. The Dinka Settlement Complex 2017. The Final Season at Gird-i Bazar and First Work in the Lower Town. Gladbeck: PeWe-Verlag.

Squitieri, A. 2017. Neo-Assyrian Period Small Finds of Gird-i Bazar, 2016. In: Radner, K., Kreppner, F. J., Squitieri, A. (eds) 2017. Unearthing the Dinka Settlement Complex.The 2016 Season at Gird-i Bazar and Qalat-i Dinka. Gladbeck: PeWe-Verlag: 155165.

Squitieri, A. 2018. The Iron Age Small Finds of the 2017 Campaigns in DLT2 and Gird-i Bazar. In: Radner, K., Kreppner, F. J., Squitieri, A. (eds) 2018. The Dinka Settlement Complex 2017. The Final Season at Gird-i Bazar and First Work in the Lower Town. Gladbeck: PeWe-Verlag: 146-172.

Barbanes Wilkinson, E., Squitieri, A., and Hashemi, Z. 2016. Small Finds. In: Radner, K., Kreppner, F. J., Squitieri, A. (eds) 2016. Exploring the Neo-Assyrian Frontier with Western Iran. The 2015 Season at Gird-i Bazar and Qalat-i Dinka. Gladbeck: PeWe-Verlag: 100-108.

Wright, K. 1992. A Classification System for Ground Stone Tools from the Prehistoric Levant. Paléorient 18: $53-81$. 